\title{
Evaluation of potential live donors for renal transplant: an evidence based approach and changing paradigms
}

\author{
Nalaka Gunawansa ${ }^{1,2}$, Ajay Sharma ${ }^{2,3}$, Ahmed Halawa ${ }^{2,4}$ \\ ${ }^{1}$ National Institute of Nephrology Dialysis and Transplant, Sri Lanka \\ ${ }^{2}$ Faculty of Health and Science, Institute of Learning and Teaching, University of Liverpool, UK \\ ${ }^{3}$ Royal Liverpool University Hospital, Liverpool, UK \\ ${ }^{4}$ Sheffield Teaching Hospitals, Sheffield, UK.
}

Key words: Kidney transplant; live donor; end stage renal failure; donor safety

\begin{abstract}
Live donor renal transplantation remains the mainstay of renal replacement therapy in most countries, including Sri Lanka. The Amsterdam consensus guidelines were considered the benchmark in evaluation of live donors and used in assessing donor suitability for over two decades. However, recent evidence has cast doubts regarding the overall safety of kidney donation warranting a closer look at donor evaluation. This review aims to look at current available evidence regarding common donor conditions and the overall need for extra vigilance in donor evaluation.
\end{abstract}

\section{Introduction}

With an ageing global population and a pandemic of diabetes, the incidence of End Stage Renal Failure (ESRF) has increased steadily across the world. Renal transplantation remains the optimal treatment, with the best outcome regarding survival and quality of life $(1,2)$. However, the rates of deceased organ donation have remained relatively static, causing an increasing disparity between the availability of organs and numbers awaiting transplantation.

Available evidence has demonstrated the benefits of Live Donor Renal Transplant (LDRT) over Deceased Donor Renal Transplants (DDRT), both regarding graft and patient survival. The reported 1-year graft and patient survival after DDRT is $88 \%$ and $95 \%$ respectively. The corresponding results for LDRT are $94 \%$ and $98 \%$ respectively, highlighting the overall superiority of LDRT in $\operatorname{ESRF}(3,4)$.

Availability of deceased donors, cultural and religious attitudes as well as the level of education regarding safety and efficacy of LDRT, contributes to the vastly different rates of live organ donation in different countries. In Sri Lanka, 80\% of transplants are LDRT. Hence, the need for an evidence based, robust, live donor evaluation protocol is imperative to

Correspondence: Nalaka Gunawansa

E-mail: vascular@drnalakagunawansa.com

Received: 30-05-2018 Accepted: 01-07-2018

(iD http://orcid.org/0000-0003-0098-3855

DOI: http://doi.org/10.4038/sljs.v36i2.8512 achieve best outcomes while ensuring utmost safety and welfare of donors.

\section{Changing paradigms}

Majority of the protocols for live donor evaluation are based on the historical Amsterdam Forum Guidelines(5). This was a landmark meeting with world experts approaching a consensus on the safety and welfare of prospective renal donors. According to available data at the time, the Amsterdam Forum established the perioperative mortality rate associated with live donor nephrectomy to be $0.03 \%(6)$. It was also emphasized that kidney donation among carefully selected healthy donors was safe with no significant increase in long-term renal insufficiency or post-donation hypertension(7). This served as a benchmark in decision making, counselling and consenting for LDRT. However, emerging data have shed new light regarding the overall safety profile of kidney donation, warranting a revisit of the earlier guidelines.

\section{Medical and Psychological evaluation and consenting}

All potential organ donors should have an individual psychological evaluation to assess their state of mind and psychological stability to proceed with organ donation $(8,9)$. This should also help in excluding coercion and donation for financial gain. Furthermore, all donors should understand that they need to proceed voluntarily and may withdraw at any time during the evaluation process with no requirement for an explanation.

The routine medical evaluation attempts to identify any obvious medical conditions that may preclude donation. It includes the screening for infections in the donor based on absolute contra-indications and regionally prevalent infections. (Table-1 and 2)

\section{Donor age}

The lower age limit for organ donation is often an arbitrary limit depending on the local legal framework. Most countries adopt this as either 18 or 21-years . In Sri Lanka, the legal age limit for organ donation is 21-years. However, the government guideline for altruistic donor ages are 25-years (male) and 30-years (female). The higher age limit for female 
Table-1. Routine screening test evaluation of donor

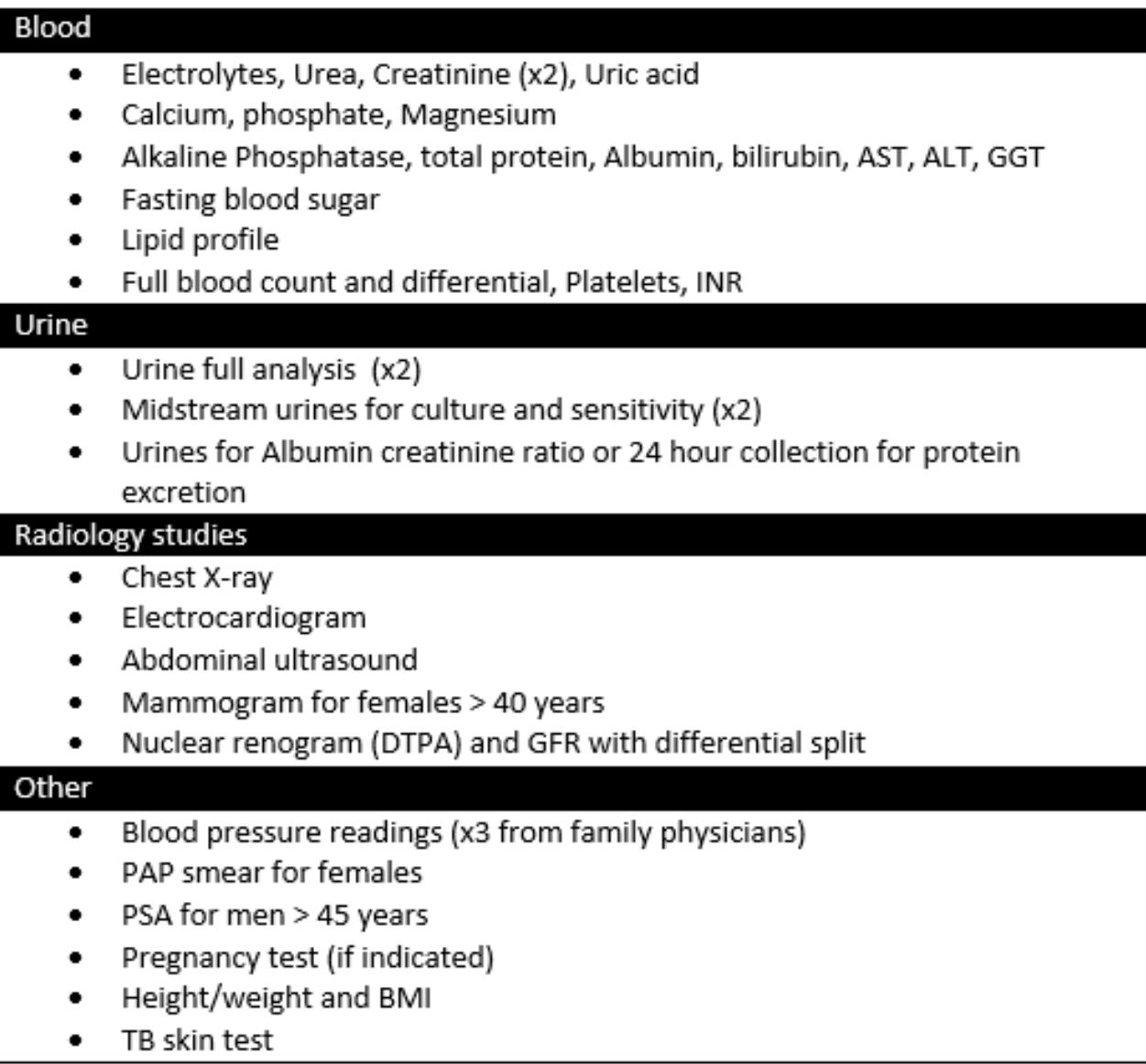

Table-2. Infection screening of donor

\begin{tabular}{|l|l|}
\hline \multicolumn{2}{|c|}{ Donor Infection screening } \\
\hline \multicolumn{1}{|c|}{ Routine tests } & Selected tests \\
\hline Urinanalysis for UTI & \\
\hline Hepatitis B; HBsAg, HBcAb & coccidiomycosis \\
\hline Hepatitis C; HCV IgG antibodies & Malaria \\
\hline HIV; HIV 1 \& 2 antibodies & Schistosomiasis \\
\hline Treponema pallidum antibodies & West nile viris \\
\hline $\begin{array}{l}\text { Cytomegalo virus (CMV) } \\
\text { - IgG and IgM }\end{array}$ & $\begin{array}{l}\text { Crutzfeldt Jakob disease } \\
\text { and variant }\end{array}$ \\
\hline Epsteinbar Virus (EBV) IgG & Strongyloides \\
\hline Toxoplasma gondii IgG & \\
\hline Tuburculin skin test & \\
\hline
\end{tabular}

donors is intended to avoid subsequent pregnancy related complications following kidney donation.

\section{Lower age limit}

The importance of a stringent lower age limit takes in to account the length of life an individual has to live postdonation, with the possibility of developing medical conditions (diabetes, hypertension, obesity and immunological disease), that could potentially lead to renal insufficiency with time (11). The Organ Procurement and Transplantation Network (OPTN) data shows that among the previous kidney donors who later developed ESRF, majority had donated over 15 years ago (12).
New data have also shown evidence of gestational complications among females who have donated and had subsequent pregnancies (13). It has demonstrated an increased incidence of pregnancy induced hypertension, eclampsia and preterm labor (14). Hence the local protocol aims to avoid such complications with raising the lower age limit for female donors and females who are planning future pregnancy.

\section{Upper age limit}

The upper age limit for donation is governed by the overall health status. With carefully screened and selected donors and age matched recipients, excellent outcomes have been achieved even with donors $>60$ years. There has been no significant increase in peri-operative morbidity or mortality among such selected older donors $(15,16)$. With the use of laparoscopic donor nephrectomy and shorter post-op recovery times, the number of older donors accepted for donation has increased in Sri Lanka over the past decade. Nevertheless, meticulous selection processes are needed to select such donors, with emphasis on cardiovascular and respiratory functional assessment. This may involve stress echocardiograms, myocardial perfusion studies and respiratory function tests.

The UNOS database 1994 to 2012, comprising over 250,000 transplants, compared outcomes from standard criteria 
deceased donors (SCDD), expanded criteria deceased donor (ECDD), and living donors (LD). Transplants from older $(>60$ years) LD had significantly lower graft and patient survival compared to those from younger LD. Nevertheless, LDRT from LD 60-70 years showed better outcomes compared to SCDD while all older LD transplants showed better outcomes compared to ECDD transplants (17). Donor general health condition and renal function rather than the chronological age should be the determinant of acceptable threshold for donation.

\section{Obesity}

Obesity is a proven risk factor for hypertension, diabetes, hypercholesterolaemia, Ischemic heart disease IHD, stroke and ESRF in the general population (18). Furthermore, obesity has been clearly linked to reduced life expectancy compared to the non-obese. Retrospective data has shown that among obese (BMI $>30 \mathrm{~kg} / \mathrm{m} 2)$ donors, $60 \%$ would develop significant proteinuria $(>3 \mathrm{~g} / \mathrm{d})$ and $30 \%$ would develop renal insufficiency, 10 years post-donation (19).

Several retrospective studies have shown a minor but definite increase in minor peri-operative complications among obese donors. These include increased operative times, increased conversion to open nephrectomy and increase of surgical site infections. There has been no definite evidence of increased donor mortality based on obesity.

While donation appears safe among the moderately obese (BMI 30-35) but otherwise healthy donors, they should be advised regarding weight reduction pre-donation and weight control post-donation. Those who fall under the very obese $(\mathrm{BMI}>35)$ category should be discouraged from donation.

\section{Hypertension}

Hypertension is a recognized risk factor for chronic kidney disease (CKD) and ESRF (20). Hence the donor evaluation should aim to identify potential donors with established hypertension. The initial clinical assessment could be by simple blood pressure measurement on three different occasions or by ambulatory blood pressure monitoring (ABPM) $(21,22)$. Established hypertension is defined as a systolic pressure $>140 \mathrm{mmHg}$ and/or diastolic pressure $>90$ $\mathrm{mmHg}$.

- Individuals with blood pressure $>140 / 90 \mathrm{mmHg}$ by ABPM are not acceptable as donors.

- Individuals with easily controlled hypertension (1-2 anti-hypertensives) who are carefully selected (age $>50$ years, GFR $\geq 80 \mathrm{~mL} / \mathrm{min} / 1.73 \mathrm{~m}^{2}$, urinary albumin $<30 \mathrm{mg} /$ day, no signs of end organ damage) are a low-risk group and may be acceptable as donors.

- End-organ damage is detected by screening for left ventricular hypertrophy, retinopathy or proteinuria. Presence of any one of these precludes donation.
- Difficult to control hypertension (requiring $>2$ antihypertensives) are also excluded from donation.

\section{Nephrolithiasis}

The worldwide prevalence of asymptomatic nephrolithiasis in the general population varies between $10-12 \%$ (23). The routine use of CT scan to evaluate potential donors has led to increased detection of such asymptomatic nephrolithiasis. When evaluating such donors, the lifetime risk of developing recurrent stones and possibility of urosepsis and obstructive uropathy with renal functional deterioration needs to be assessed.

Symptomatic stone bearers in the general population, carry a $50 \%$ risk of recurrent stones within 5-years (24). Hence, donors with current symptomatic nephrolithiasis should be precluded from donation.

Donors with a history of single stone may be considered if:

- Metabolic screening excludes significant metabolic abnormality that increases the risk of recurrent stones (hypercalcuria, hyperuricemia, metabolic acidosis, hypocitraturia, cystinuria, hyperoxaluria)

- CT scan shows no evidence of multiple stones, nephrocalcinosis

- Donors with minor correctable metabolic abnormalities (hypocitratuiria, hypercalciuria) may be considered once treated, after careful counselling

- Donor with asymptomatic current stone/s may be considered if:

- Metabolic screening and CT imaging is negative as above

- Current largest stone is $<1.5 \mathrm{~cm}$, potentially removable during transplant

- If more than one stone, they should all be limited to one kidney and that kidney should be extracted for donation

The following are contra-indications to donate:

- Nephrocalcinosis on imaging

- Multiple bilateral stones

- Large stones $(>1.5 \mathrm{~cm})$

- Stone types that have high recurrence rates (cystine, struvite stones)

Small stones $(<5 \mathrm{~mm})$ may be safely left behind and transplanted with minimal risk. It is likely to be spontaneously passed with post-transplant polyuria in the recipient, especially if located in the upper or middle calyx. Any larger stone or stones in the lower calyx should ideally be extracted ex-vivo by flexible ureteroscopy (9).

\section{Diabetes}

All prospective donors should have a fasting blood sugar 
(FBS) or HBA1C assessment in the preliminary workup. A FBS of $>7 \mathrm{mmol} / \mathrm{L}(\mathrm{HBA} 1 \mathrm{C}>6.5 \%)$ indicates established diabetes while 6.1-6.9 mmol/L indicates impaired glucose tolerance (IGT) and warrants further testing with oral glucose tolerance test (OGTT). Prospective donors with additional risk factors for type-2 diabetes (family history, obesity, history of gestational diabetes, hyperlipidaemia, hypertension) should also have a mandatory OGTT. A 2-hour OGTT value $>11.1 \mathrm{mmol} / \mathrm{L}$ indicates established diabetes.

Established diabetes is considered a contra-indication to donation among most centers. Impaired glucose tolerance is a relative contra-indication and may proceed to donation provided there are no additional risk factors and there is suitable follow-up plan available in the local set-up.

\section{Cardiac assessment}

Similar to any major operation, donor nephrectomy requires a preliminary cardiac assessment to determine the fitness for operation. Furthermore, it also allows evaluation of baseline cardiac status and thereby makes assessments regarding the possible long-term effects of living with a single kidney.

All prospective donors should have a detailed clinical examination and electrocardiogram as a baseline. A transthoracic echocardiogram is recommended to supplement the above findings. Currently, there is no evidence of stress echocardiograms in all donors, especially those who are at low cardiac risk $(9,25)$.

Donors who are at higher risk (smoking, hyperlipidaemia, personal or family history of IHD, low exercise capacity) need individualised discussion at the multi-disciplinary meeting with contribution from cardiologists. Accordingly, further targeted cardiac testing can be done including stress echocardiogram and CT coronary calcium scoring.

\section{Familial diseases}

Presence of familial inherited diseases should be excluded during live-related renal transplant. It requires a detailed family history, pedigree and a high index of suspicion regarding subclinical renal disease and extra-renal manifestations. This allows to rule out the possibility of subclinical disease in the donor which may lead to renal insufficiency post-donation.

\section{Autosomal Dominant Polycystic Kidney Disease (ADPKD)}

ADPKD is the commonest familial renal disease resulting in ESRF. Where a first-degree family member of a patient is being evaluated for donation, extreme care is needed to exclude disease in the donor.

Ultra-sound scan (USS) criteria for diagnosing ADPKD and thereby precluding donation include (26);

- $\geq 3$ renal cysts in total (age 15-39),
- $\geq 2$ cysts in each kidney (age 40-59),

- $\geq 4$ cysts in each kidney (age $\geq 60$ ).

A negative USS in those $>40$ years excludes the disease and is safe to proceed with donation. In those aged 20-40, more sensitive imaging with $\mathrm{CT} / \mathrm{MRI}$ is required. $\mathrm{CT} / \mathrm{MRI}$ evidence of $>10$ cysts is considered positive while $<10$ cysts is used for exclusion of disease. When imaging results are equivocal, genetic screening for the ADPKD mutation should be performed. Donor Renal Function

The screening test for donor renal function is measurement of serum creatinine and estimated Glomerular Filtration Rate (eGFR). More accurate functional assessment requires 24-hour urinary collection and clearance of 51Cr-EDTA (or inulin) (9).

Assessment of split renal function by radio-isotope study allows for identification of contribution from each kidney for overall function. This is especially useful in the presence of significant size discrepancy between kidneys (>10\%). Considered along with other anatomical factors, the kidney with lower GFR is usually selected for donation.

\section{Normal kidney function and change with aging}

The GFR in a healthy individual remains stable up to about 40 years, after which it shows an age-related decline; 6.6 - 7.7 $\mathrm{mL} / \mathrm{min} /$ year in males and females respectively(27). Postdonation, although the remnant kidney shows a compensatory increase in function, it does not match pre-donation GFR. Donors have been shown on average to have a GFR loss of 26 $\mathrm{mL} / \mathrm{min}$ post-donation, achieving $65-75 \%$ of the pre-donation $\operatorname{GFR}(28,29)$. This information is used in deciding the threshold renal function for donation, ensuring the prospective donors GFR remains in the lower normal range for age.

Earlier donor guidelines were based on the findings that, despite a reduced GFR, the incidence of ESRD among donors were either similar or even lower than the general population. However, newer studies that compared donor outcomes with those of matched non-donors who would have otherwise been eligible to donate have shed new light in this regard. Muzaale and colleagues compared 96,000 donors (mean follow-up 9 years) with matched healthy controls(30). The risk of ESRD was 31/10,000 among donors and 4/10,000 among controls. Lifetime risk of ESRD was 90/10,000 (donors), 326/10,000 (general population), and 14/10,000 (matched non-donor controls)(31). Hence although the risk of long-term ESRF is not significantly higher than the general population, it is higher compared to well-matched non-donor controls (Figure-1). This becomes pertinent when considering younger donors with greater life-years ahead post-donation. Hence the guidelines on the lowest threshold GFR for donation are based on donor age. (Table-3) 
Table-3. Recommended age-specific GFR threshold for donation

\begin{tabular}{|l|c|c|}
\hline \multirow{2}{*}{$\begin{array}{c}\text { AGE } \\
\text { (Years) }\end{array}$} & \multicolumn{2}{|c|}{$\begin{array}{c}\text { Threshold GFR } \\
\left(\mathbf{m l} / \mathbf{m i n} / \mathbf{1 . 7 3 \mathbf { m } ^ { 2 }} \text { ) }\right.\end{array}$} \\
\cline { 2 - 3 } & Male & Female \\
\hline $20-29$ & 90 & 90 \\
\hline $30-34$ & 80 & 80 \\
\hline 35 & 80 & 80 \\
\hline 40 & 80 & 80 \\
\hline 45 & 80 & 80 \\
\hline 50 & 80 & 80 \\
\hline 55 & 80 & 75 \\
\hline 60 & 76 & 70 \\
\hline 65 & 71 & 64 \\
\hline 70 & 67 & 59 \\
\hline 75 & 63 & 54 \\
\hline 80 & 58 & 49 \\
\hline
\end{tabular}

\section{Proteinuria}

Proteinuria is an independent risk factor for ESRF and cardiovascular mortality. Hence, all potential donors require accurate assessment and quantification of proteinuria. According to Amsterdam guidelines, the threshold for the acceptable donation was 24-hour urinary protein excretion of $<300 \mathrm{mg}(32)$. Although it remains the gold standard, a 24-hour urinary collection is cumbersome and laden with errors. Hence currently recommended alternative tests are spot urine assessment for albumin/creatinine ratio (ACR) or protein/creatinine ratio (PCR) (9).

Overt proteinuria (ACR $>30 \mathrm{mg} / \mathrm{mmol}, \mathrm{PCR}>50 \mathrm{mg} / \mathrm{mmol}$ ) is a marker of future cardiovascular mortality and progression to ESRF, considered an absolute contra-indication to donate. Moderate proteinuria (ACR 3-30 mg/mmol, PCR 15-50 $\mathrm{mg} / \mathrm{mmol}$ ) is a relative contra-indication. Benign causes of proteinuria (urinary tract infection UTI, febrile illness, vigorous exercise, orthostatic proteinuria) need to be considered in otherwise healthy donors. If identified, the cause needs to be rectified and the test repeated to establish complete resolution before donating. In suspected orthostatic proteinuria, a sample immediately after waking needs to be assessed before donation.

\section{Hematuria}

All donors need to have basic urinalysis including at least two separate reagent strip tests in the screening stage. Non-visible haematuria $(\mathrm{NVH}) /($ microscopic haematuria) has a prevalence of up to $20 \%$ in the general population(33). Persistent NVH hematuria in a donor requires more rigorous investigation after excluding benign causes such as infection, strenuous exercise and menstruation.

Further investigation of NVH aims to exclude urological disease (calculi, inflammation, carcinoma) and glomerular disease. These include urine culture (including tuberculosis), cytology and CT imaging. If these are negative, a flexible cystoscopy is indicated for all potential donors $>40$ years $(9)$. If still negative and the donor remains committed, a renal biopsy is needed to exclude glomerular disease. The presence of red cell casts, proteinuria and dysmorphic red cells are suggestive of glomerular pathology. A positive glomerular disease on biopsy will preclude donation.

Thin basement membrane disease (TBMD) can be diagnosed in $10-50 \%$ of patients undergoing biopsy for persistent $\mathrm{NVH}(34)$. This is considered benign and donors who have donated with TBMD have not demonstrated any definite progression to ESRF. Nevertheless, such donors should only be considered in exceptional circumstances and should be educated regarding the limited long-term available data.

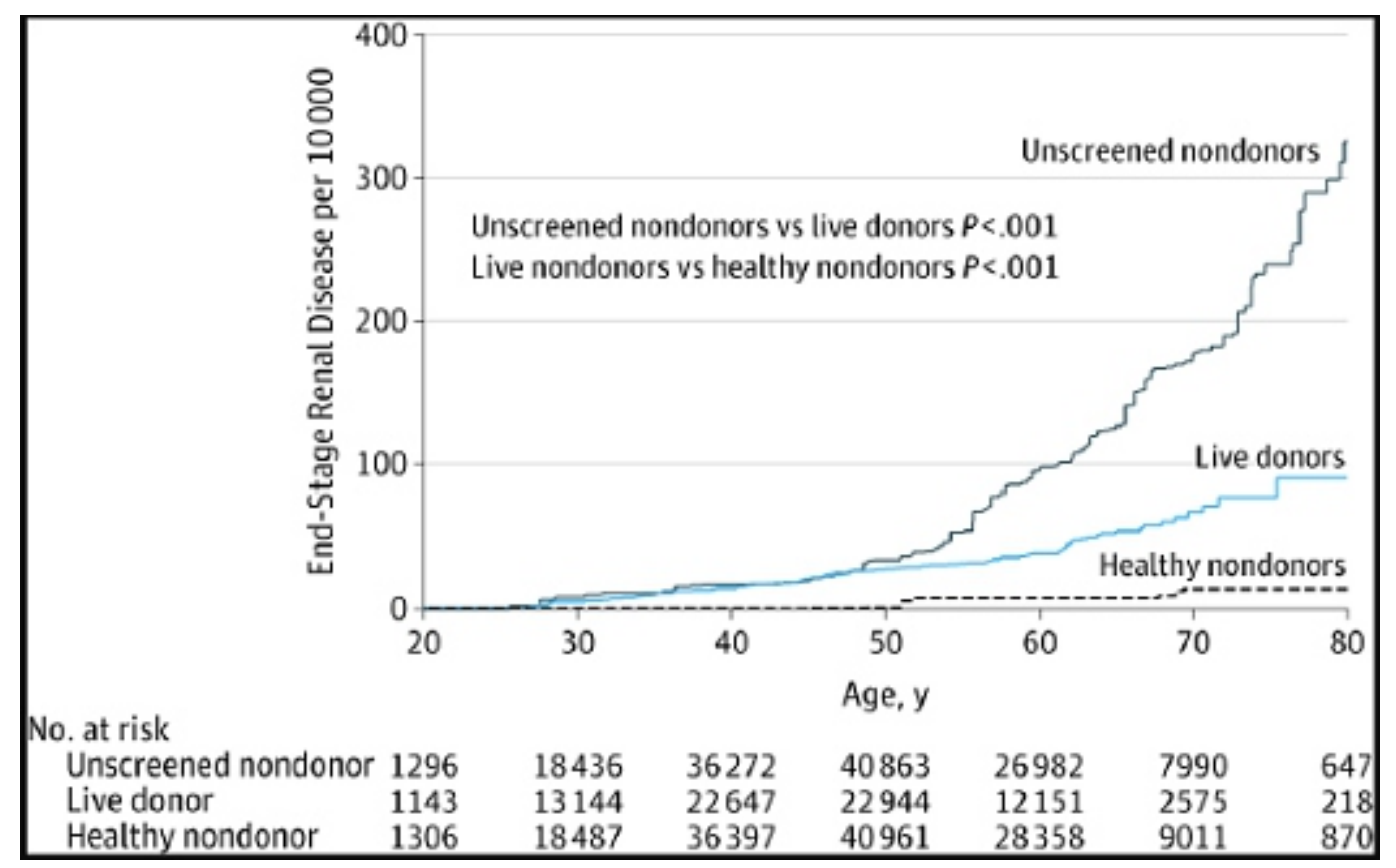

Figure-1. Risk of ESRF post-donation ${ }^{(31)}$ 


\section{Pyuria}

Significant pyuria (>10 wnite celis/mm3) should be investigated, and donation should only proceed if it can be attributed to a benign reversible cause and confirmation of such after appropriate treatment. Asymptomatic pyuria is common in the general population $(2.6 \%$ of men, $13.9 \%$ of women) $(35,36)$. The commonest reason is UTI which needs to be excluded by urinary culture.

The most frequent reasons for sterile pyuria include atypical infections (fungal, tuberculosis etc.), partially treated UTI, calculi, stents, prostatitis etc. In the local set-up with a higher prevalence of tuberculosis, genito-urinary tuberculosis should be excluded by 3 consecutive early morning samples. If no identifiable cause is found for persistent pyuria, it warrants renal biopsy to exclude interstitial nephritis or pyelonephritis, both of which are contra-indications for donation.

\section{Radiologic Evaluation}

Contrast CT abdomen including CT angiogram is mandatory before donation. This can visualize the renal parenchyma, the presence of cysts, calculi, arterial, venous and ureteric anatomy. It allows precise characterisation of the anatomy in deciding suitability, best operative approach and which kidney to harvest for donation etc.

Kidney donation is contraindicated in the presence of a gross parenchymal anomaly, horseshoe kidney, multiple bilateral cystic disease or complex septated cyst, angiomyolipoma or nephrocalcinosis, multiple bilateral calculi.

\section{Donor Smoking, alcohol and substance abuse}

As for any major surgery, active smoking becomes a risk factor for increase peri-operative morbidity. It also becomes an added risk factor for those who are obese or hypertensive. The Amsterdam forum recommends smoking cessation at least 4-weeks before the donation which is the standard practice in our programme. Furthermore, these donors should be enrolled in smoking cessation clinics for sustained abstinence to minimise future risks.

Donors with a history of regular alcohol use should be evaluated to exclude hepatic insufficiency that would preclude donation(37). Potential donors who are engaged in substance abuse are excluded from donation.

\section{Hypercoagulability}

Prospective donors with a history of venous thromboembolism (VTE), family history of thrombophilia or females with recurrent miscarriages should have a thrombophilia screen. This includes an assessment of protein $\mathrm{C}$ and $\mathrm{S}$ levels, antithrombin III, factor-V Leiden mutation, anti-cardiolipin antibody, lupus anticoagulant, prothrombin gene mutation and homocysteine levels. History of recurrent VTE or positive thrombophilia requiring chronic anticoagulation are contraindications for donation.

\section{Conclusion}

Live donors remain the mainstay of renal transplantation in most countries including Sri Lanka. While a more comprehensive standardized deceased donor program is evolving, live donors still far outweigh the deceased donors. Although live donation remains safe, meticulous evaluation and screening are required to ensure long-term safety and well-being of the donor. Furthermore, stringent post-donation follow-up with attention to renal function as well as overall general medical health will contribute to minimising longterm risks to such donors.

Table-4. Contra-indications to donate

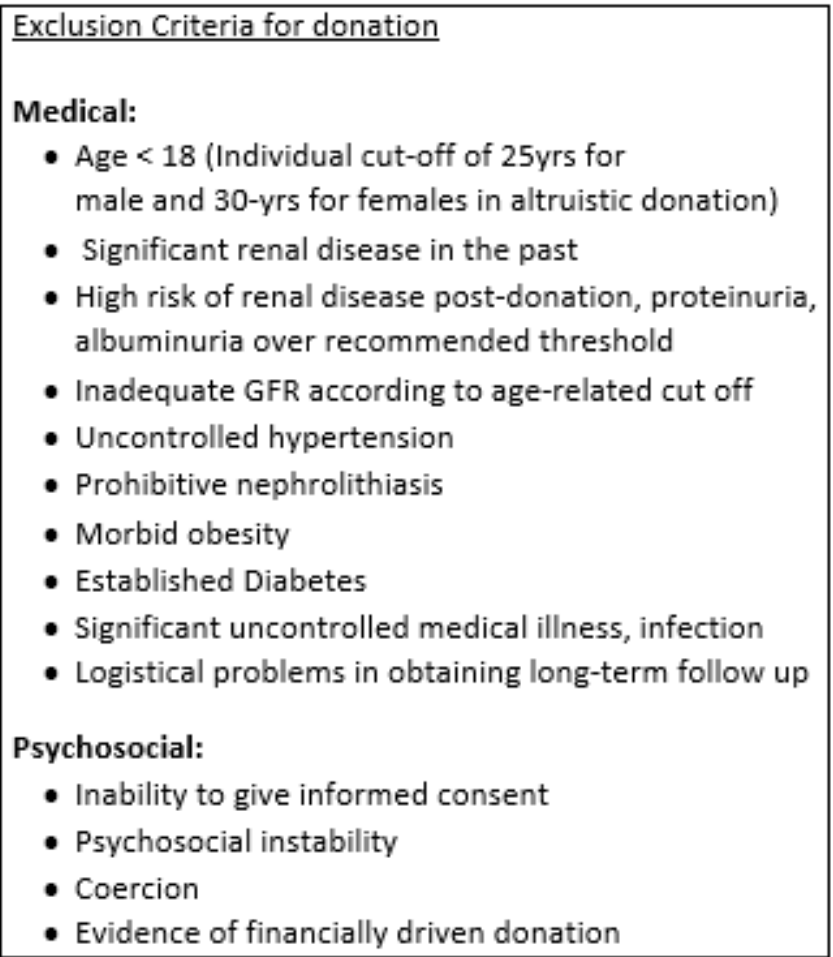

All authors disclose no conflict of interest. The study was conducted in accordance with the ethical standards of the relevant institutional or national ethics committee and the Helsinki Declaration of 1975, as revised in 2000.

\section{References}

1. Kasiske B, Zeier M, Craig J. KDIGO clinical practice guideline for the care of kidney transplant recipients. Am J Transplant. 2009;9(3):S1-155.

2. Abecassis M, Bartlett ST, Collins AJ, Davis CL, Delmonico FL, Friedewald JJ, et al. Kidney transplantation as primary therapy for end-stage renal disease: a National Kidney Foundation/Kidney Disease Outcomes Quality Initiative (NKF/KDOQITM) conference. Clin J Am Soc Nephrol. 2008;3(2):471-80. doi.org/10.2215/CJN.05021107

3. Collins AJ, Foley RN, Herzog C, Chavers B, Gilbertson D, Ishani A, et al. US renal data system 2012 annual data report. American Journal of Kidney Diseases. 2013;61(1 SUPPL.1). doi.org/10.1053/j.ajkd.2012.11.031

4. Collins A J, Foley R N, Herzog C, Chavers B M, Gilbertson D, 
Ishani A, et al. Excerpts from the US Renal Data System 2009 Annual Data Report. Am J Kidney Dis. 2010;55(1 Suppl 1).

doi.org/10.1053/j.ajkd.2009.10.009

5. Delmonico F, Council of the Transplantation Society. A Report of the Amsterdam Forum On the Care of the Live Kidney Donor: Data and Medical Guidelines. Transplantation. 2005 Mar 27;79(6 Suppl):S53-66.

6. Davis CL. Living Kidney Donors: Current State of Affairs. Adv Chronic Kidney Dis. 2009;16(4):242-9.

doi.org/10.1053/j.ackd.2009.05.007

7. Abecassis M, Adams M, Adams P, Arnold RM, Atkins CR, Barr $\mathrm{ML}$, et al. Consensus statement on the live organ donor. JAMA. 2000;284(22):2919-26. doi.org/10.1001/jama.284.22.2919

8. Dew MA, Jacobs CL, Jowsey SG, Hanto R, Miller C, Delmonico FL. Guidelines for the psychosocial evaluation of living unrelated kidney donors in the United States. In: American Journal of Transplantation. 2007. p. 1047-54. doi.org/10.1111/j.1600-6143.2007.01751.x

9. BTS / RA Living Donor Kidney Transplantation Guidelines 2018.

10.Delmonico FL, Dew MA. Living donor kidney transplantation in a global environment. Vol. 71, Kidney International. 2007. p. 608-14. doi.org/10.1038/sj.ki.5002125

11.Kher A, Mandelbrot DA. The living kidney donor evaluation: ocus on renal issues. Clin J Am Soc Nephrol. 2012 Feb;7(2):366-71. doi.org/10.2215/CJN.10561011

12.Gibney EM, King AL, Maluf DG, Garg AX, Parikh CR. Living kidney donors requiring transplantation: Focus on African Americans. Transplantation. 2007;84(5):647-9. doi.org/10.1097/01.tp.0000277288.78771.c2

13.Garg AX, Nevis IF, McArthur E, Sontrop JM, Koval JJ, Lam NN, et al. Gestational Hypertension and Preeclampsia in Living Kidney Donors. N Engl J Med. 2015;372(2):124-33. doi.org/10.1056/NEJMoa1408932

14.Majak GB, Reisæter AV, Zucknick M, Lorentzen B, Vangen S, Henriksen T, et al. Preeclampsia in kidney transplanted women; Outcomes and a simple prognostic risk score system. PLoS One. 2017;12(3):e0173420. doi.org/10.1371/journal.pone.0173420

15.Dols LFC, Kok NFM, Roodnat JI, Tran TCK, Terkivatan T, Zuidema WC, et al. Living kidney donors: Impact of age on longterm safety. Am J Transplant. 2011;11(4):737-42. doi.org/10.1111/j.1600-6143.2011.03465.x

16. Toyoda M, Yamanaga S, Kawabata C, Hidaka Y, Inadome A, Arakane F, et al. Long-term safety of living kidney donors aged 60 and older. In: Transplantation Proceedings. 2014. p. 318-20. doi.org/10.1016/j.transproceed.2013.11.019

17.Mandelbrot DA, Pavlakis M, Danovitch GM, Johnson SR, Karp SJ, Khwaja K, et al. The medical evaluation of living kidney donors: A survey of US transplant centers. Am J Transplant. 2007;7(10):2333-43. doi.org/10.1111/j.1600-6143.2007.01932.x

18.Johansen KL, Lee C. Body composition in chronic kidney disease. Vol. 24, Current Opinion in Nephrology and Hypertension. 2015. p. 268-75.

19.Chertow GM, Hsu C, Johansen KL. The Enlarging Body of Evidence: Obesity and Chronic Kidney Disease. J Am Soc Nephrol. 2006 Jun 1;17(6):1501-2. doi.org/10.1681/ASN.2006040327

20.Cerasola G, Mulè G, Nardi E, Cusimano P, Palermo A, Arsena R, et al. Clinical correlates of renal dysfunction in hypertensive patients without cardiovascular complications: The REDHY study. J Hum Hypertens. 2010;24(1):44-50. doi.org/10.1038/jhh.2009.41

21.Textor SC, Taler SJ, Larson TS, Prieto M, Griffin M, Gloor J, et al. Blood pressure evaluation among older living kidney donors. J Am Soc Nephrol. 2003;14(8):2159-67.

doi.org/10.1097/01.ASN.0000077346.92039.9C
22. Young A, Storsley L, Garg AX, Treleaven D, Nguan CY, Cuerden MS, et al. Health outcomes for living kidney donors with isolated medical abnormalities: A systematic review. Am J Transplant. 2008;8(9):1878-90.

doi.org/10.1111/j.1600-6143.2008.02339.x

23.Koh LT, $\mathrm{Ng} \mathrm{FC,} \mathrm{Ng} \mathrm{KK}$. Outcomes of long-term follow-up of patients with conservative management of asymptomatic renal calculi. BJU Int. 2012;109(4):622-5. doi.org/10.1111/j.1464-410X.2011.10329.x

24.Burgher A, Beman M, Holtzman JL, Monga M. Progression of nephrolithiasis: long-term outcomes with observation of asymptomatic calculi. J Endourol. 2004;18(6):534-9.

doi.org/10.1089/end.2004.18.534

25.European Renal Best Practice. ERBP Guideline on kidney donor and recipient evaluation and perioperative care. Nephrol Dial Transplant. 2013;28(suppl 2):ii1-ii71.

26.Pei Y, Hwang Y-H, Conklin J, Sundsbak JL, Heyer CM, Chan W, et al. Imaging-Based Diagnosis of Autosomal Dominant Polycystic Kidney Disease. J Am Soc Nephrol. 2015;26:746-53. doi.org/10.1681/ASN.2014030297

27.Weinstein JR, Anderson S. The aging kidney: physiological changes. Adv Chronic Kidney Dis. 2010 Jul;17(4):302-7. doi.org/10.1053/j.ackd.2010.05.002

28.Denic A, Glassock RJ, Rule AD. Structural and Functional Changes With the Aging Kidney. Adv Chronic Kidney Dis. 2016 Jan;23(1):19-28. doi.org/10.1053/j.ackd.2015.08.004

29.Cho HJ, Choi SW, Bae WJ, Kim SJ, Hong SH, Lee JY, et al. Change in renal function following laparoscopic donor nephrectomy using 99 mTc-diethylenetriaminepentaacetic acid scan. World J Urol. 2015 May 25;33(5):719-23. doi.org/10.1007/s00345-014-1408-0

30. Muzaale AD, Massie AB, Wang M-C, Montgomery RA, McBride MA, Wainright JL, et al. Risk of End-Stage Renal Disease Following Live Kidney Donation. JAMA. 2014 Feb 12;311(6):579. doi.org/10.1001/jama.2013.285141

31. Segev DL, Muzaale AD, Caffo BS, Mehta SH, Singer AL, Taranto SE, et al. Perioperative mortality and long-term survival following live kidney donation. JAMA. 2010;303(10):959-66. doi.org/10.1001/jama.2010.237

32.Groth C, Noe L. A Report of the Amsterdam Forum On the Care of the Live Kidney Donor : Data and Medical Guidelines Alliance with the World Health Organization. 2005;79(2):53-66.

33. Kelly JD, Fawcett DP, Goldberg LC. Assessment and management of non-visible haematuria in primary care. Vol. 338, BMJ (Online). 2009. p. 227-32.

34.Savige J, Rana K, Tonna S, Buzza M, Dagher H, Wang YY. Thin basement membrane nephropathy. Vol. 64, Kidney International. 2003.p. 1169-78. doi.org/10.1046/j.1523-1755.2003.00234.x

35.Yacoub R, Akl NK. Urinary tract infections and asymptomatic bacteriuria in renal transplant recipients. J Glob Infect Dis. 2011;3(4):383-9. doi.org/10.4103/0974-777X.91064

36. Alwall N, Lohi A. A POPULATION STUDY ON RENAL AND URINARY TRACT DISEASES. Acta Med Scand. 2009 Apr 24;194(1-6):529-35. doi.org/10.1111/j.0954-6820.1973.tb19486.x

37.Tonnesen H, Rosenberg J, Nielsen HJ, Rasmussen V, Hauge C, Pedersen IK, et al. Effect of preoperative abstinence on poor postoperative outcome in alcohol misusers: randomised controlled trial. BMJ. 1999;318(7194):1311-6. doi.org/10.1136/bmj.318.7194.1311

38.Biglarnia A, Bergqvist D, Johansson M, Wadström J. Venous thromboembolism in live kidney donors-a prospective study. Transplantation. 2008;86(5):659-61. doi.org/10.1097/TP.0b013e3181817d36 